\title{
Obesity, leptin, and deregulation of microRNA in lipid metabolisms: their contribution to breast cancer prognosis
}

\author{
Kartika W. Taroeno-Hariadi ${ }^{*}$ (D), Mardiah S. Hardianti ${ }^{1} \mathbb{D}$, Hemi Sinorita $^{2} \mathbb{C}$ and Teguh Aryandono ${ }^{3}$
}

\begin{abstract}
Obesity and Metabolic Syndrome have been associated with cardiovascular, diabetes and cancer incidence. Obesity is a state of inflammation. There are cross-talks between adipocyte, adipokines, pro-inflammatory cytokines, insulin, leptin, and other growth factors to initiate signals for proliferation, anti-apoptosis, and angiogenesis. Those networks lead to cancer initiation, promotion, progression, and metastasis. Post menopause women with breast cancer commonly have overweight, obesity, and metabolic syndrome, which are previously reported as conditions to be associated with breast cancer prognosis. MicroRNAs (miRNAs), small non-coding RNA that regulate gene expression, are known to play important roles either in metabolic or carcinogenesis process in patients with breast cancer. Some miRNAs expressions are deregulated in persons either with obesity, breast cancer, or breast cancer with co-morbid obesity. This literature review aimed at reviewing recent publications on the role of obesity, leptin, and microRNA deregulation in adverse prognosis of breast cancer. Understanding the influence of deregulated miRNAs and their target genes in patients with breast cancer and obesity will direct more studies to explore the potential prognostic role of obesity in breast cancer from epigenetic points of view.
\end{abstract}

Keywords: Obesity, Lipid metabolism, microRNA, Breast cancer, Prognosis

\section{Background}

Breast cancer has become the most common malignancy in women all over the world, with estimated 2,088,089 new cases and 626,679 deaths in 2018 [1]. Due to its high incidence and mortality rate, various prevention strategies have been developed in risk identification and stratification, screening, early detection and diagnosis, personalized treatment, and identification of biomarkers.

Many studies proved the importance of metabolic biomarkers in cancer risk and prognosis, including in breast cancer [2-7]. Metabolic biomarkers are used clinically in predicting the responses to certain cancer treatments,

\footnotetext{
*Correspondence: kartika.widayati@ugm.ac.id

${ }^{1}$ Division of Hematology and Medical Oncology, Department of Internal Medicine, Faculty of Medicine, Public Health, and Nursing, Universitas Gadjah Mada, Farmako Street, Sekip Utara, Yogyakarta 55281, Indonesia Full list of author information is available at the end of the article
}

assessing drug toxicity, monitoring efficacy, and evaluating pharmacodynamics. Identification of metabolic markers has been explored and widely applied since the last two decades. Some of the major concerns involve the comorbidities of obesity and Metabolic Syndrome, which are known as risk factors for cardiovascular disease, diabetes, and for cancer as well [8]. Obesity increases the risk for breast cancer and research found that $46.2 \%$ of patients with breast cancer are obese [8]. Some studies also reported that obesity influenced the prognosis of breast cancer [8].

Many theories have been raised to explain the role of obesity in cancer. It is well-established that there is a crosstalk between tumor microenvironment, adipocytes, adipokines, estrogen, and proliferation of cancer cells [9]. Cancer cells also influence surrounding tissue to support their growth, cell cycle, invasion, and migration [10]. Studies on leptin, which is a protein hormone secreted 
by adipocytes, and identified as a candidate biomarker for breast cancer progression, have shown unconvincing results, and none of the hypotheses concerning the role of leptin or other adipokines in breast cancer progression have been totally conclusive.

MicroRNA (miRNA) is a non-coding, small molecule RNA that has the function to modulate expression of many protein coding-genes, thereby contributing to both physiologic and pathologic processes. The roles of miRNA as a regulator for both the metabolic process and carcinogenesis in breast cancer are abundantly reported $[11,12]$.

This literature review aimed to reviewing recent developments and publications concerning the role of obesity, leptin, and miRNA deregulation in adverse prognosis of breast cancer. We reviewed all publication from PubMed database using the terms (("breast neoplasms"[MeSH Terms] AND ("leptin"[MeSH Terms] AND ("obesity"[MeSH Terms] OR ("metabolic syndrome"[MeSH Terms] AND ("micrornas" [MeSH Terms]. We consider it is important to explore substantial available data, analyze, and unfolded the complexity of several miRNAs that regulate the expression of certain genes involved in interaction between metabolic and mitogenic pathway in breast cancer.

\section{Obesity and metabolic syndrome increase breast cancer risk and progression}

Obesity related hyperinsulinism and high circulating estrogen levels may explain the association between adipocytes and breast cancer cells. In post-menopausal women, adipocytes become the main source of aromatase contributing to the increased number of adipocytes in obese women, in which the more the increase, the greater the androgen aromatization into the hormone estrogen. In obese post-menopausal women, there are increased levels of plasma insulin and insulin-like growth factor-1 (IGF-1) that have mitogenic effects on breast cancer cells [13]. Obesity and excess fat present as chronic inflammation, insulin resistance, adipokines imbalance, and increased estrogen signaling [14].

Epidemiology studies show there are associations between obesity-related inflammation and breast cancer incidence, prognosis, and mortality rate. Obesity, defined as increased Body Mass Index $(\mathrm{BMI}) \geq 30$, is related to breast cancer risk, with relative risk (RR) ranges from 1.5-2.5 [15]. Increased risk of breast cancer in post-menopausal women with increased BMI are largely caused by hormonal increases of free-estradiol [16, 17]. Patient characteristics such as post menopause, obese, unhealthy metabolism, and central obesity in women have been shown to increase the risk for developing breast cancer. $[2,6,14,18]$.

Metabolic Syndrome, defined as having three or more metabolic components (obesity or increased waist circumference, hyperglycemia, hypertriglyceridemia, lowHDL, or hypertension) $[19,20]$, is also associated with breast cancer risk. The hazard ratio of Metabolic Syndrome in breast cancer risk in Japan is reported to be 2.87 (CI 1.67-4.94), and the hazard ratio for post-menopausal breast cancer is 6.73 (CI 2.93-25.43) [21].

Obesity is also associated with poorer survival of breast cancer $[22,23]$. High BMI has been proven to be an independent prognostic factor in triple negative breast cancer (TNBC) as well as in luminal type breast cancer [16, 24]. Additionally, higher Waist-to Hip (WTH) ratio is a poorer prognostic factor in luminal type breast cancer [25]. Chan et al. reported a meta-analysis of 82 studies which involved more than 200,000 breast cancer patients [26]. This study reported that obese patients have poorer total mortality $(\mathrm{HR}=1.41,95 \% \mathrm{CI} 1.29-1.53)$ and poorer breast cancer-specific mortality $(\mathrm{HR}=1.35,95 \%$ CI $1.24-$ 1.47) compared to normal weight patients [26].

\section{Estrogen and breast cancer}

Estrogen is a steroid hormone that have several physiological functions such as: regulation of menstrual cycle and reproduction, development of breast tissue and sexual organ, bone density, brain function, energy balance, cholesterol mobilization and lipid homeostasis, $\beta$-cell function survival, insulin sensitivity, and control of inflammation [27]. Estrogen is widely known to have an important role in promoting and maintaining breast cancer tissue. In most breast cancer, estradiol (E2), the predominant type of estrogen in circulation, and Estrogen Receptor (ER $\alpha$ or ER $\beta$ ) complex (E2-ER complex) are involved in malignant transformation. E2-ER complex activates transcriptional processes and/or signaling events to control gene expression. These actions are mediated through direct binding to specific sequences in gene promoters such as Estrogen Response Element (ERE) and other transcription factors (TFs) inside nucleus (direct genomic pathway) or by mechanisms that do not involved direct binding to DNA (indirect genomic pathway). Indirect genomic pathway involved action of E2 through membrane bound ER (G protein coupled Estrogen Receptor, GPCR1), which in turn recruited adaptor proteins interaction, second messenger production, cAMP regulation, and Mitogen Activated Protein Kinase (MAPK) and PI3K-Akt (Phosphatidyl Inositol-3 kinase/serine threonine kinase) pathway activation. These signaling cascades activation results in indirect 
changes of gene expression. Genes expression needed for cellular proliferation and growth functions are also activated by ER-ligand independent (estrogen independent) pathway through protein kinase signaling from growth factor receptors (IGFR, EGFR, HER) or by ER independent manner. There is crosstalk, and deregulation between ER, Insulin like Growth Factor Receptor (IGF-R), Growth Factors Receptors (EGFR, HER), and other RTK (Receptor Tyrosine Kinase) signaling to initiate and promote proliferation and metastasis of breast cancer cells. [28, 29].

\section{Adipose tissue, adipokines, and breast cancer}

The precise mechanisms linking obesity and breast cancer remain unclear. One possible mechanism is the crosstalk between adipose tissue, microenvironment, and breast cancer cells. Adipose tissue may produce a group of polypeptide growth factors and cytokines such as adiponectin, leptin, Interleukin-6 (IL-6), Tumor Necrosis Factor-alpha (TNF- $\alpha$ ), Plasminogen Activator Inhibitor-1 (PAI-1), and resistin that may underlie such association [20]. Current studies showed that in obese women the concentrations of circulating adipokines are elevated except for adiponectin, which is involved in glucose regulation and the metabolism of fat [30].

Recent publications have indicated that adipokines play an important role in the association between obesity and postmenopausal breast cancer [31]. In breast tissue there may be interactions between adipokines, estrogen, growth factor signaling, and hormones that create a microenvironment which promotes proliferation, growth, and survival of breast cancer cells [31, 32]. Recent research established that there is interaction between leptin and adiponectin signaling pathways in MCF-7 breast cancer cell lines, in which proliferation is induced by leptin and suppressed by adiponectin [33].

\section{Leptin and breast cancer}

Leptin is a protein hormone produced by adipocytes, the placenta, and mammary epithelium. Leptin is a $16 \mathrm{kD}$ molecular weight protein encoded by obese genes. Leptin has several functions in controlling metabolic, reproductive, and immunologic processes, as well as angiogenesis, hematopoiesis, and lipid oxidation, and also acts as a proinflammatory factor. Plasma leptin level increases alongside with BMI [34-36].

Niu et al. [37] reported in their review and meta-analysis that leptin level plays a significant role in patients with breast cancer compared to healthy controls. Leptin enhances the proliferation of breast cancer cells by inhibiting the pro-apoptosis machinery, upregulating antiapoptosis genes, modulating tumor microenvironment, and by increasing sensitivity to estrogen. Leptin in several studies of animal models is associated with breast cancer tumorigenesis. Leptin levels, both in circulating plasma or expression in breast cancer tissue, are reported to have association with breast cancer progression Leptin and leptin receptor are overexpressed in breast cancer tissue probably due to hypoxia, IGF, estradiol, and insulin overexposure [38].

\section{Mechanisms of obesity, metabolic syndrome, and deregulation of leptin in the breast cancer pathogenesis}

There are cross-talks between obesity and carcinogenesis. They involve inflammatory pathways and are characterized by the dysregulation of metabolism. Obesity will increase aromatization of estrogen in adipose tissue, which in turn modulates sensitivity to insulin. In the process, leptin production is increased and as a result, a hyperinsulinemia condition occurs to modulate the mitogenic and anti-apoptotic effect.

Hyperinsulinemia is a condition where the cells decrease their sensitivity to insulin. Hyperinsulinemia can increase bioactivity of IGF-I, which involves binding to IGF-IR and a hybrid receptor of insulin receptor, isoform-A/IGF-I. Signals through these receptors may increase cellular proliferation via PI3K deregulation. PI3K will induce Akt and activate mTOR to stimulate protein synthesis, cell growth, and mitotic preparation. Dysregulation of mTOR is commonly found in various cancer including breast cancer. PTEN, a tumor suppressor gene, is often mutated or dysregulated so that proliferation signals through PI3K and IGF-I are uninhibited.

The stromal tumor microenvironment consists of matrix, fibroblast, vasculature, and immune cells play an important role in breast cancer carcinogenesis. Adipocytes are the main component of breast cancer's stromal tissue. Many studies revealed an interaction between adipocytes and cancer cells, and their reciprocal adaptation will promote cancer progression. Adipocyte cells will induce cancer cells to proliferate, grow, migrate, and develop treatment resistance. Meanwhile, cancer cells will secrete paracrine and endocrine signals to mobilize metabolic substrates, especially free fatty acids, and to accumulate adipocyte cells around the tumor. Adipocyte cells will serve tumor cells by supporting them with metabolic substrates, lipid signal agonists, and also growth factors [9].

Accumulation of adipocytes will increase aromatase and in turn estrogen synthesis will be increased. Obesity, hyperinsulinemia, and increased IGF-I will decrease sex hormone binding globulin (SHBG) leading 
to increasing of estrogen bioavailability. Estrogen pathways are synergized with IGF-IR to activate MitogenActivated Protein Kinase (MAPK). Estrogen activates IGF-IR and Insulin Receptor Substrate (IRS-1 and IRS2 ), which increases phosphorylation of IRS-1 and activation of MAPK [9].

Adiposity status is represented directly by leptin and its level in circulation is increased in obese or overweight patients. Leptin resistance is found in obesity and is caused by several mechanisms such as: defect access of leptin to its receptor (decrease receptor expression or impairment of post-receptor signaling including epigenetic process) [39], defect in the leptin blood-brain barrier, or weakening of leptin signaling due to inactivation of JAK-STAT pathway (via inhibition of suppressor of cytokine-signaling-3), endoplasmic reticulum stress, and inflammation [40]. Dysregulation of leptin signaling leads to more leptin secretion by adipocyte tissue.

Leptin acts on their receptors named leptin receptor Ob-R. Just as other cytokine receptors, the leptin receptor is a member of the cytokine I receptor superfamily. There are many isoforms of Ob-R, including: Ob- $\mathrm{Ra}$, Ob-Rb, Ob-Rc, Ob-Rd, Ob-Re, and Ob-Rf. Ob-R a, c, d, and $f$ have a short form of the cytoplasmic domain that activates MAPK pathways. The MAPK pathways, PI3K/ phosphodiesterase 3B (PDE3B), and cyclic adenosine monophosphate (AMP) have roles in carcinogenesis. The full and long cytoplasmic domain is owned by the $\mathrm{Ob}-\mathrm{Rb}$ isoform, and this type of isoform activates the JAK-STAT3 pathway. Activation of JAK-STAT3 is important for the nuclear function of leptin, as well as for gene expressions regulating cellular proliferation and antiapoptosis. The isoform of Ob-Re can be found in circulation. When the JAK-STAT pathway is weakened, leptin still maintains its function in cell proliferation by activating PI3K/AKT, and MAPK pathways [40]. Leptin has become a marker of tumorigenesis in overweight, obesity, and post-menopausal women [40]. Leptin also has the ability to interfere with tamoxifen action in estrogen receptor positive breast cancer cell lines, due to its activation of ERK1/2 and STAT3 signal transduction pathways under estradiol stimulation [41].

Regulation of gene expression and molecular signaling leading to carcinogenesis process in obesity related breast cancers are modified by expression of various microRNA in concert.

\section{MicroRNA deregulation in obesity, metabolic syndrome, breast cancer}

MicroRNAs (miRNA or miR) can modulate expressions of protein-coding genes. Abundant studies showed that miRNA play an important role in adipose metabolism, inflammatory or proliferative signaling as well as in carcinogenesis. There are many miRNAs that have a role in obesity and adipogenesis such as: Let-7, miR-15a, miR-17-92, miR-21, miR-24, miR-27, miR-30, miR31, miR-103, miR-107, miR-125b, miR-130, miR-138, miR-143, miR-150, miR-200, miR204/211, miR-210, miR-221, miR-222, miR-326, miR-335, miR-355, miR378,miR-448, and miR-519d [42]. Those miRNAs target adipogenesis process involving various gene expression, transcription factors (PPAR- $\gamma, \mathrm{C} / \mathrm{EBP}$ ), several signaling pathway (Wnt/catenin, TGF- $\beta$ superfamily, IGF, and insulin), and extracellular matrix [43]. Several miRNAs may target the same genes however, one single miRNA may also be able to modulate many different target genes playing important role in obesity-related breast cancer.

Some miRNAs regulate adipogenesis by targeting PPAR- $\gamma$ [43]. MiR-143 known to increase pre-adipocyte differentiation, target PPAR- $\gamma$ and inhibit ERK5 (Extracellular Regulating Kinase 5) [44]. ERK, a member of MAPK, promotes cell proliferation, angiogenesis, cell differentiation, and survival [44]. ERK5 does not have function in adipogenesis [43], but have prognostic impact in breast cancer [45].

Interaction of PPAR- $\gamma$ ligand, rosiglitazone, and IGFBP-3 decrease proliferation of breast cancer cells line MCF-7, MDA-MB 468, MDA-MB 231 [46]. PPAR- $\gamma$ are reported to act as tumor suppressor by regulate proliferation, apoptosis, and cellular differentiation [47]. Overexpression of miR-130 are often found in adipose tissues of obese women along with low expression of PPAR- $\gamma$ [43] that raised hypothesis that miR-130 suppressed adipogenesis. On the other hand, overexpression of miR-130 inhibit PTEN in human breast cancer cell, and activate AKT phosphorylation [48].

MiR-21 enhanced adipogenesis of human adipose tissue-derived stromal cells (HASC) by modulating TGF- $\beta$ [49], and targeting STAT3 signaling [50]. Those 2 signaling pathways has interaction with PPAR- $\gamma$ signaling [47]. Treatment of breast cancer cell with oxidized LDL (mimicking hyperlipidemic condition) will induce inflammation and proliferation signaling mediated by miR-21 overexpression. Overexpression of miR-21 inhibit PTEN and activate AKT phosphorylation [51].

Obesity induce overexpression of miR-24-3p that in turn repress HDL uptake, lipid metabolism, and steroid hormone intake by inhibiting Scavenger Receptor B-1 (SRB1) [52]. Overexpression of miR-24-3p inhibit p27Kip1 [53] and Bim expression therefor increase growth and proliferation of breast cancer [54].

Inflammation induced specific miRNA expression in adipocyte. MiR-155 is overexpressed in obese adipocyte 
with inflammation state, in line with NFkB. It is probably due its ability to target PPAR- $\gamma$ [55]. MiR-155 promotes proliferation of breast cancer cells by targeting $\mathrm{SOC} 1$ and MMP6 [56].

Mir-210 promotes adipogenesis by suppressing Wnt signaling [57], and in breast cancer it is upregulated by hypoxic condition and target E-cadherin and HIF1- $\alpha[58$, 59].

Li et al. reported that miR221/222 level are increasing in women with diabetes melitus type 2 and postmenopausal breast cancer [60]. MiR221/222 facilitate inflammation in adipocyte tissue and reduce insulin sensitivity by targeting ER $\alpha$ and GLUT4. In breast cancer mir-222 inhibit PTEN, and p27Kip1, activate Akt, inhibit lncRNAGS 5, and MYC [61-66].

Genome-wide analysis reveals miR-3184-5p and miR-181c-3p as a critical regulator for adipocytesassociated breast cancer [67]. Upregulation of miR3184-5p target FOXP4- NOTCH induced EMT pathway in co-culture of mature adipocyte breast cancer cell. Downregulation of miR-1881c-3p reduce inhibition of PPAR- $\gamma$ and in turn stimulate breast cancer cells proliferation [67].

MiR-26 targets PTEN/PI3K/Akt to improve insulin sensitivity [68]. MiR-26 acts as a tumor suppressor miR by targeting SLC7A11 [69]. Depletion of miR-26 a/b will increase proliferation of ER-positive breast cancer cell with or without estrogen stimulus. MiR-26 targets estrogen-related genes such as CHD1, GREB1, KPNA2. c-MYC is necessary for inhibiting miR-26 expression induced by estrogen [70].

In chronic inflammation state of obesity, IFN- $\gamma$ signaling restricts expansion of white adipose tissue (WAT) and decrease insulin sensitivity [71]. miR-30 targets transcription factor STAT1 to limit action of IFN- $\gamma$ [71]. It also promotes adipocyte differentiation by targeting Plasminogen activator Inhibitor (PAI-1) and Activin Receptor like Kinase 2 (ALK2) [72]. MiR-30a expression in obese adipocyte is repressed. In breast cancer miR-30 inhibits Cyclin E2 result in cell cycle arrest [73].

miR-148-3p targets DNMT1 (a gene involved in DNA methylation) which regulate adipocyte differentiation and obesity [74] and also targets WNT-1/ $\beta$-catenin, AKT/ERK, IGF-1R signaling pathways in breast cancer [75].

miR-302b maintain SOX2 and c-MYC to produce cytokine-induced cancer stem cell-like properties in breast cancer cell co-cultured with immature adipocyte [76]; whilst miR-302b in breast cancer targets RUNX2, an activator of PI3K/AKT signaling [77].

Let-7 is downregulated in obesity and in vivo it targets HMGA2 [42]. In breast cancer let-7 inhibit HMGA2,
MYC, JAK-STAT-3, Caspase-3, RAS, CCND2, ER $\alpha$ [78-80].

Mir-27 are overexpressed in obesity due to hypoxic condition. MiR-27 family blockade PPAR- $\gamma$ function, activate Wnt1 signaling [81] and in turn suppress GLUT-4 and PI3K-signaling leading to hyperglycemia, insulin resistant, and hyperlipidemia. [82]. MiR-27 in breast cancer act as tumor suppressor miR by targeting SPRY1, BAK, FOXO1, and CBLB/GRB2 [83-85].

MiR-34a overexpressed in visceral fat of overweight/ obese subjects are associated with insulin resistant and metabolic inflammation. Lipid loaded mature adipocytesecreted exosomes transport miR-34a to macrophage and suppress anti-inflammatory M2 phenotype by repressing Kruppel-like factor 4 (Klf-4) [86] Mir-34a is key mediator in exacerbating obesity related systemic inflammation and metabolic dysregulation [86] As contrary, previous studies reported that miR-34a were downregulated in human breast tissue [87]. MiR-34a acts as tumor suppressor miR by downregulating its target genes such as BCL-2 and SIRT1 [88] and Notch1 [89] Wnt/ $\beta$-catenin signaling pathway [90], fra-1 [91], MYC [92].

Several miRs regulate obesity and breast cancer and their target genes are summarized in Table 1.

Leptin expressions and functions are also regulated by the orchestration of various miRNA. Stimulation of leptin may modulate several types of miRNAs, both oncogenic and tumor suppressor miRs. Leptin induced oncogenic miRs (miR-21, miR-96, miR-31, miR-182) and reduced tumor suppressor miRs (miR-143, miR-26b, miR-27b, MiR-489) [93]. Increased leptin expression is significantly associated with increase post-menopausal breast cancer risk [93].

Deregulation of some miRNAs in breast cancer are widely documented in various studies. Some of them act as oncogenic miRs that regulate the process of carcinogenesis and metastasis, whilst others act as tumor suppressor miRs that suppress oncogenesis and the proliferation of cancer cells. Some miRNAs expressions are specific for the histologic type of breast cancer [94, 95] Let-7a, let-7b, and miR-324 are specifically upregulated in luminal type breast cancer. MiR-142-5p, miR-155 are downregulated in luminal B type. MiR-106a, miR-18a, miR-155, miR-135b are upregulated in basal type breast cancer. Interestingly, miR-187 is upregulated in HER-2 breast cancer, but miR-130a, miR-30a-3p, miR-30a-5p, and miR-224 are downregulated [95].

It is important to identify deregulated miRNAs in breast cancer patients with obesity or metabolic dysfunction which would have an impact on their prognosis.

Figure 1 summarize the crosstalk between metabolic and mitogenic process in obesity related breast cancer 
Table 1 MicroRNA (miR) Deregulation in Obesity and Breast Cancer

\begin{tabular}{|c|c|c|c|}
\hline MiR & Target genes and functions in obesity & Target genes and functions in breast cancer & References \\
\hline 21 & $\begin{array}{l}\text { TGF- } \beta \text { R2 inhibition } \\
\text { PTEN inhibition, reduced AP-1 }\end{array}$ & $\begin{array}{l}\text { PTEN inhibition, } \\
\text { PI3K/Akt activation }\end{array}$ & [49-51] \\
\hline $24-3 p$ & $\begin{array}{l}\text { Inhibit SR-B1 that regulate cholesterol uptake, increase } \\
\text { HMGCR, DHCR24 and SREBP2 }\end{array}$ & Inhibit p27Kip1, inhibit Bim, cell cycle proliferation & {$[52-54]$} \\
\hline 155 & Upregulated in inflammation targets PPAR- $\gamma$ & Downregulate SOC-1, upregulate MMP6 & {$[55,56]$} \\
\hline 210 & Inhibit Wnt signaling, increase adipogenesis & E-cadherin, HIF1-a, metastasis, proliferation & {$[57-59]$} \\
\hline $221 / 222$ & Era, GLUT4, reduced insulin stimulation of glucose uptake & $\begin{array}{l}\text { Inhibit PTEN and p27(Kip), activate Akt, ER-alpha, inhibit } \\
\text { IncRNA GAS5 down regulate MYC, increase proliferation, cell } \\
\text { cycle, survival }\end{array}$ & {$[60-66]$} \\
\hline $3184-3 p$ & $\begin{array}{l}\text { FOXP4-NOTCH induced EMT pathway proliferation of MABC } \\
\text { cells }\end{array}$ & & [67] \\
\hline let-7 & Inhibit HMGA2, inhibit preadipocyte proliferation & $\begin{array}{l}\text { Inhibit HMGA2, MYC, JAK-STAT-3, Caspase-3, RAS, CCND2, Era } \\
\text { decrease invasion tumor suppressor function }\end{array}$ & [78-80] \\
\hline $26 b$ & Inhibit PTEN/PI3KAAKT pathway to modulate insulin sensitivity & Serpin B2, anti-metastasis and anti-invasion & [68-70] \\
\hline $27 \mathrm{~b}$ & Control lipid metabolisms inhibit PPAR- $\gamma$ & $\begin{array}{l}\text { FOXO1, ST14 } \\
\text { BAK } \\
\text { SPRY2 } \\
\text { TMEM170B } \\
\text { CBLB/GRB2 } \\
\text { apoptosis, cell-cycle } \\
\text { checkpoint }\end{array}$ & {$[81-85]$} \\
\hline 30a & Suppression of STAT1 to limit Interferon $\gamma$-signaling & Cyclin E2; anti proliferative G1, cell cycle arrest & {$[71-73]$} \\
\hline $181 c-3 p$ & PPARa; reduced inhibition of PPARa, BC proliferation & & {$[67]$} \\
\hline $143-3 p$ & PPAR-y, AP2, leptin pathway, ERK5 & $\begin{array}{l}\text { DNMT3A, PTEN hypermethylation, increase TNFRS F10c meth- } \\
\text { ylation, KRAS, AKT1, BCL2 }\end{array}$ & [44] \\
\hline $148 a-3 p$ & inhibit DNMT1 which is correlated with obesity & $\begin{array}{l}\text { WNT-1, } \beta \text {-catenin, MMP-7, TCF-4, BCl-2, caspases, anti metas- } \\
\text { tasis, anti invasion by regulating Wnt/ } \beta \text {-catenin signaling } \\
\text { pathway }\end{array}$ & {$[74,75]$} \\
\hline $302 b$ & Maintain SOX2 and c-Myc by targeting repressor of c-Myc & $\begin{array}{l}\text { Target RUNX2, that activate PI3KJAKT signaling and regulate } \\
\text { proliferation }\end{array}$ & {$[76,77]$} \\
\hline $34 a$ & Inhibit macrophage M2 induced adipose inflammation & $\begin{array}{l}\text { Inhibit BCL2, CCND1, MYC, E2F3, CDK6, SIRT1 } \\
\text { anti-apoptosis }\end{array}$ & {$[86-92]$} \\
\hline
\end{tabular}

and the potential role of some microRNA that regulate both processes.

Some investigators developed $\mathrm{miR}$ signatures to evaluate their role as prognostic markers in breast cancer. For example, miR-21, miR-30c, miR-181a, miR-125b, miR-7, miR-200a, miR-135b, miR-22 and miR-200c signatures are tested in hormone positive, HER2- negative breast cancer and provide reliable prognostic models [96]. To date, there was no difference found in miR expressions between obese postmenopausal patients with breast cancer and normal weight groups in terms of miR-17-5p, miR-195-3p and miR-221-3p [97].
On the contrary, there are many miRs upregulated in obesity but acted as tumor suppressor miR (i.e. miR30, miR-448, and miR-519). According to author personal opinion this might explain some paradoxes found in women with obesity without compromising survival outcome. Several studies showed obesity does not compromise survival outcome in some patients with breast cancer [98-100]. The complexities network of miRs function and regulation make it more difficult to select the signature of miRs as prognostic markers in breast cancer with obesity and metabolic deregulation.

Further exploration is needed to identify certain miR signatures to be developed as a prognostic model in obese/overweight breast cancer. 


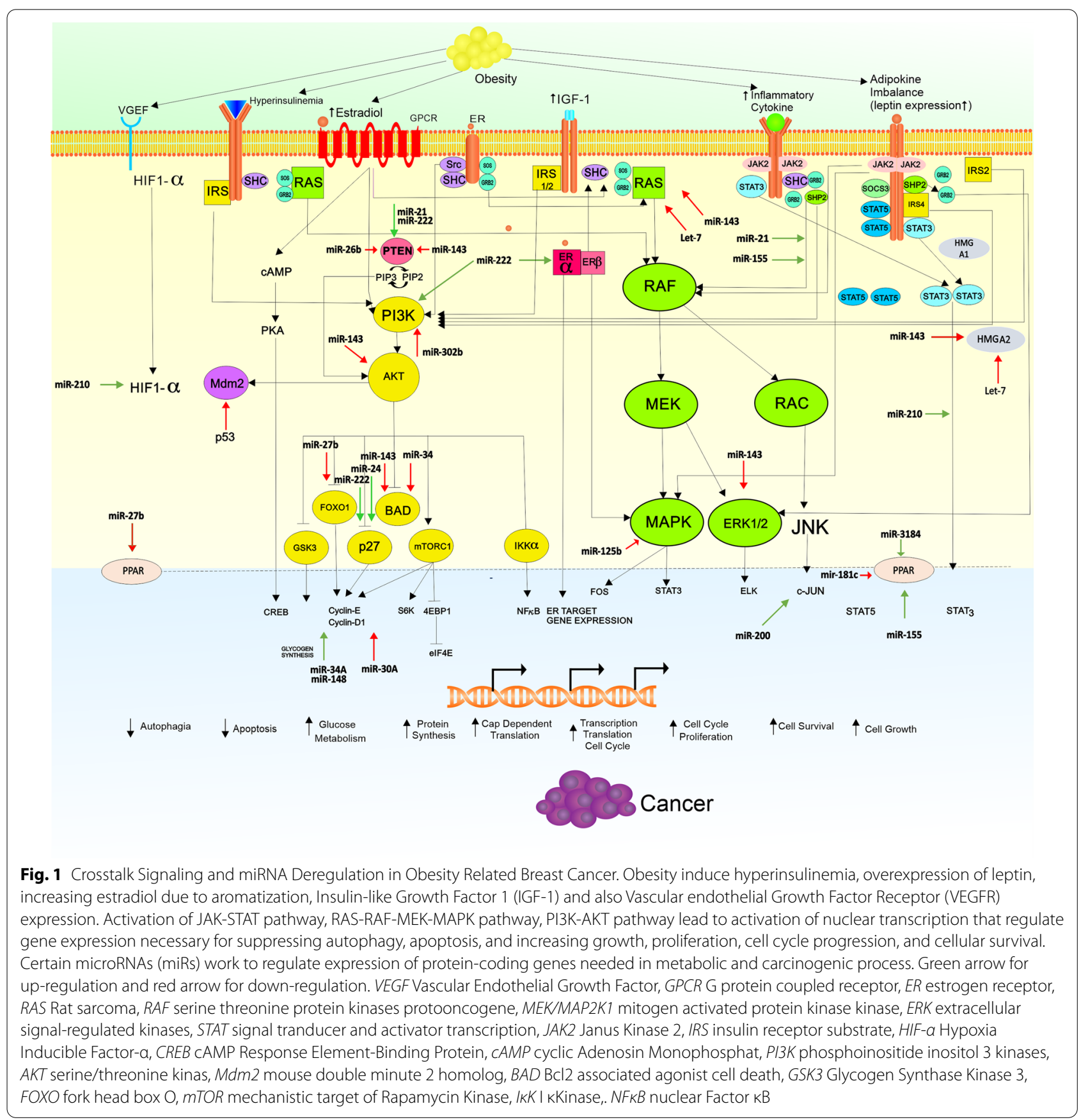

\section{Conclusions}

Theoretically obesity may induce breast cancer through deregulation of some miRs that regulate the metabolic process, cellular inflammation, and proliferation signaling, pathways via adipokines, insulin-like growth factors, insulin, cytokines, and estrogen signaling. Various miRs are deregulated in patients with breast cancer with co-morbid obesity, suggesting there are some sharing of mechanisms involved in adipogenesis and carcinogenesis. Presently, there is no single miR that can predict prognosis or serve as a single biomarker. Some combination of miR signatures have the potential for a set of prognostic markers specific for the different types of breast cancers, as well as breast cancer with co-morbid obesity, but this possibility needs to be further explored and validated. 


\section{Abbreviations}

AKT: AKT Serine/Threonine Kinase; BAD: BCl2 associated agonist cell death; BAK: BCL-2 homologous antagonist killer; BCL2: B cell lymphoma 2; BIM: BCL2L11 protein 11; CAMP: Cyclic Adenosin Monophosphat; CCND1: Cyclin D1 gene; CCND2: Cyclin D2; CCNE2: Cyclin E2 gene; CREB: cAMP Response Element-Binding Protein; DHCR24: 24 Dehydrocholesterol reductase; DNMT2: DNA methyltransferase; E2F3: Transcription factor E2F3; EGFR: Epidermal Growth Factor Receptor; EphA4: Ephrine-type A receptor 4; ER: Estrogen receptor; ERK: Extracellular signal-Regulated Kinases; Foxo1: Fork head box O 1; Fra-1: Fos-related antigen 1; GAS5: Growth Arrest Specific 5; GPCR: G protein coupled receptor; GRb2: Growth factor receptor bound 2; GSK3: Glycogen Synthase Kinase 3; HDAC: Histone deacetylase; HIF1-a: Hypoxia Inducible Factor-a; HMAG2: High motility Group 2; HMGCR: HMG-CoA reductase (3 hydroxy-3 methyl- glutaryl-co enzyme A reductase); HUR: Human antigen R (Embrionic Lethal, Abnormal Vision Drosophila Like-1 or ELAVL 1); IGF: Insulinlike Growth Factor; IGF-1R: Insulin-like Growth Factor 1 Receptor; IKK: Ik Kinase; IRS: Insulin Receptor Substrate; JAK2: Janus Kinase 2; KRAS: Kirsten Rat Sarcoma Virus; KIf-4: Kruppfel-like Factor 4; MAP2K1/MEK1: Mitogen Activated Protein Kinase Kinase; MAP3K2: Mitogen Activated Protein Kinase 2; MdM2: Mouse double minute 2 homolog; MMP6: Matrix Metallo Peptidase-9; MSH2: Muts homolog 2; mTOR: Mechanistic Target Of Rapamycin Kinase; MYB: (myeloblastosis) protooncogene like 1 and Myb related protein B; C-MYC: Cellular MyelocytomatosisNFkB: Nuclear Factor Kb; NFkB: Nuclear Factor kB; P16Ink4a: p16 cyclin dependent kinase inhibitor 2 A; P21/Kip1: CDK inhibitor p21/p27; PI3K: Phosphatidyl inositol-3 kinase; PPAR- $\gamma$ : Peroxisome Proliferator Activated Receptor $\gamma$; PTEN: Phosphatase and tensin homolog; RAS: Rat sarcoma; RAF 1: Rapid accelerated Fibrosarcoma; RUNX1: Runt related transcription factor 3; SIRT1: Sirtuin 1; SLC7A11: Cysteine glutamine transporter; SPRY2: Sprouty homolog 2; SREBP2: Sterol regulatory element binding protein 2; ST14: Suppressor of tumorigenicity 14; STAT: Signal Transducer and Activator Transcription; TIMP3: Tissue Inhibitor of MetalloProteinase-3; TMEM170B: Transmembrane protein 170B; TNC:Tenascin-C gene; TPM1:Tropomyosin gene; WIM/ TWF1: Twinfilin Actin Binding Protein; ZEB1, ZEB2: Zinc finger e-box-binding homeobox 1 and 2 .

\section{Acknowledgements}

We thank to Nina Fitria Ariesta MD and Rezky Suryo for preparing figure.

\section{Authors' contributions}

KWT was the major contributor in concepting and writing the manuscript, HS corrected and reviewed in endocrinology part, MSH read and revised the manuscript, TA read the final draft. All the authors read and approved the final manuscript.

\section{Funding}

The authors do not received funding for preparing this review article.

\section{Availability of data and materials}

Not applicable.

\section{Ethic approval and consent to participate}

Not applicable.

\section{Consent for publication}

Not applicable.

\section{Competing interest}

The authors declare that they have no competing interest.

\section{Author details}

${ }^{1}$ Division of Hematology and Medical Oncology, Department of Internal Medicine, Faculty of Medicine, Public Health, and Nursing, Universitas Gadjah Mada, Farmako Street, Sekip Utara, Yogyakarta 55281, Indonesia. ${ }^{2}$ Division of Endocrinology, Department of Internal Medicine, Faculty of Medicine, Public Health, and Nursing, Universitas Gadjah Mada, Yogyakarta, Indonesia. ${ }^{3}$ Division of Surgical Oncology, Department of Surgery, Faculty of Medicine, Public Health, and Nursing, Universitas Gadjah Mada, Yogyakarta, Indonesia.
Received: 16 October 2020 Accepted: 29 December 2020

Published online: 22 January 2021

\section{References}

1. Bray F, Ferlay J, Soerjomataram I, Siegel RL, Torre LA, Jemal A. Global cancer statistics 2018: GLOBOCAN estimates of incidence and mortality worldwide for 36 cancers in 185 countries. Cancer J Clin. 2018;68:394-424.

2. Esposito K, Chiodini P, Calao A, Lenzi A, Giugliano D. Metabolic Syndrome and risk of cancer: a systematic review and meta-analysis. Diabetes Care. 2012;35:2402-11.

3. Esposito K, Chiodini P, Capuano A, Bellastella G, Majorino MI, Rafaniello C, et al. Metabolic syndrome and postmenopausal breast cancer: systematic review and meta-analysis. Menopause. 2013;20:1301-9.

4. Berrino F, Villarini A, Traina A, Bonanni B, Panico S, Mano MP, et al. Metabolic Syndrome and breast cancer prognosis. Breast Cancer Res Treat. 2014;147:159-65.

5. Kabat GC, Kim MY, Lee JS, Ho GY, Going SB, Beebe-Dimer J, et al. Metabolic obesity phenotypes and risk of breast cancer in postmenopausal women. Cancer Epidemiol Biomarkers Prev. 2017;26:1730-5.

6. Bitzur R, Brenner R, Maor E, Antebi M, Ziv-Baran T, Segev S, et al. Metabolic syndrome, obesity, and risk of cancer development. Eur J Intern Med. 2016;34:89-93.

7. Gunter MJ, Xie X, Xue X, Kabat GC, Rohan TE, Wassertheil-Smoller S, et al. Breast cancer risk in metabolically normal but overweight postmenopausal women. Cancer Res. 2015;75:270-4.

8. Buttros Dde A, Nahas EA, Vespoli Hde L, Uemura G, de Almeida Bda R, Nahas-Neto J, et al. Risk of Metabolic Syndrome in post-menopausal breast cancer survivors. Menopause. 2013;20:448-54

9. Braun S, Bitton-Worms K, LeRoith D. The link between the metabolic syndrome and cancer. Int J Biol Sci. 2011;7:1003-15.

10. Hoy AJ, Balaban S, Saunders DN. Adipocyte-tumor cell metabolic crosstalk in breast cancer. Trends Mol Med. 2017:23:381-9.

11. Kaur KK, Allahbadia GN, Singh M. An update on microRNA's and metabolic regulation with future therapeutic potentials regarding diagnosis and treatment of obesity, Metabolic Syndrome and other related disorders. J Health Inform Med. 2015;6:184.

12. Yahya SMM, Elsayed GH. A summary for molecular regulations of miRNAs in breast cancer. Clin Biochem. 2015;48:388-96.

13. Gershuni VM, Ahima RS, Tchou J. Obesity and breast cancer: a complex relationship. Curr Surg Reports. 2016;4:14.

14. Morimoto LM, White E, Chen Z, Chlebowski RT, Hays J, Kuller L, et al. Obesity, body size, and risk of postmenopausal breast cancer: The Women's Health Initiative (United States). Cancer Causes Control. 2002;13:741-51.

15. Endogenous Hormones and Breast Cancer Collaborative Group. Body mass index, serum sex hormones, and breast cancer risk in post-menopause women. J Natl Cancer Inst. 2003;95:1218-26.

16. Endogenous Hormones and Breast Cancer Collaborative Group. Circulating sex hormones and breast cancer risk factors in postmenopausal women: reanalysis of 13 studies. British J Cancer. 2011;105:709-22.

17. Chen H, Ding A, Wang M. Impact of central obesity on prognostic outcome of triple negative breast cancer in Chinese women. Springer Plus. 2016;5:594-603.

18. Park YM, White AJ, Nichols HB, O'Brien KM, Weinberg CR, Sandler DP, et al. The association between metabolic health, obesity phenotype and the risk of breast cancer. Int J Cancer. 2017;140:2657-66.

19. Huang PL. A comprehensive definition of Metabolic Syndrome. Disease Models Mechanisms. 2009;2:231-7.

20. Grundy SM. Metabolic Syndrome Update. Trends Cardiovascular Med. 2016;26:364-73.

21. Osaki Y, Taniguchi S, Tahara A. Metabolic syndrome and incidence of liver and breast cancers in Japan. Cancer Epidemiol. 2012;36:141-7.

22. Robinson PJ, Bell RJ, Davis SR. Obesity is associated with poorer prognosis in women with hormone receptor positive breast cancer. Maturitas. 2014;79:279-86.

23. Jiralerspong S, Goodwin PJ. Obesity and breast cancer prognosis: evidence, challenges, and opportunities. J Clin Onco. 2016:34:4203-16. 
24. Calip GS, Malone KE, Gralow JR. Metabolic syndrome and outcomes following early stage breast cancer. Breast Cancer Res Treat. 2014;148:363-77.

25. Sun X, Nichols HB, Robinson W, Sherman ME, Olshan AF, et al. Troester MA Post-diagnosis adiposity and survival among breast cancer patients: influence of breast cancer subtype. Cancer Causes Control. 2015;12:1803-11.

26. Chan DS, Vieira AR, Aune D. Body mass index and survival in women with breast cancer: systematic literature review and meta-analysis of 82 follow-up studies. Ann Oncol. 2014;25:1901-14.

27. Mauvais-Jarvis F, Clegg DJ, Hevener AL. The role of estrogens in control of energy balance and glucose homeostasis. Endocr Rev. 2013;34(3):309-38.

28. Velloso FJ, Bianco AFR, Farias JO, Torres NEC, Ferruzo PY, Anschau V, et al. The crossroads of breast cancer progression: insights into the modulation of major signaling pathways. Onco Targets Ther. 2017;10:5491-524.

29. Fuentes N, Silveyra P. Estrogen receptor signaling mechanisms. Adv Protein Chem Struct Biol. 2019;116:135-70.

30. Gui Y, Pan Q, Chen X, Xu S, Luo X, Chen L. The association between obesity related adipokines and risk of breast cancer: a meta-analysis. Oncotarget. 2017;8:75389-99.

31. Gu L, Chao C, Fu J. Serum adiponectin in breast cancer: a meta-analysis. Medicine 2018; 97:29(e11433).

32. Li J, Han X. Adipocytokines and breast cancer. Curr Probl Cancer 2018:42:208-14

33. Jarde T, Caldefie-Chezet F, Goncalves-Mendes N, et al. Involvement of adiponectin and leptin in breast cancer: clinical and in vitro studies. Endocr Relat Cancer. 2009;16:1197-210.

34. Garofalo C, Surmacz E. Leptin and cancer. J Cell Physiol. 2006;207:12-22.

35. Hu X, Juneja SC, Maihle NJ, Cleary MP. Leptin - a growth factor in normal and malignant breast cells and for normal mammary gland development. J Natl Cancer Inst. 2002;94:1704-11.

36. Surmacs E. Obesity hormone leptin: a new target for breast cancer? Breast Cancer Res. 2007;9:301.

37. Niu J, Jiang L, Guo W, Shao L, Liu Y, Wang L, et al. The association between leptin level and breast cancer: a meta-analysis. PLoS ONE.2013; 8(6).

38. Garofalo C, Koda M, Cascio S, Sulkowska M, Kanczuga-Koda L, Golaszewska J, et al. Increased expression of leptin and the leptin receptor as a marker of breast cancer progression: possible role of obesity-related stimuli. Clin Cancer Res. 2006;12:1447-53.

39. Crujeiras AB, Carreira MC, Cabia B, Andrade S, Amil M, Casanueva FF. Leptin resistance in obesity: An epigenetic landscape. Life Sci. 2015;140:57-63.

40. Schmidt S, Monk JM, Robinson LE, Mourtzakis M. The integrative role of leptin, oestrogen and the insulin family in obesity-associated breast cancer: potential effects of exercise. Reviews. 2015;16:473-87.

41. Yom CK, Lee K, Han W, Kim S, Kim HS, Moon Bl, et al. Leptin as a potential target for estrogen receptor-positive breast cancer. J Breast Cancer. 2013;16:138-45.

42. Kasiappan R, Rajarajan D. Role of microRNA regulation in obesity-associated breast cancer: nutritional perspectives. Adv Nutr. 2017;8:868-88.

43. Zhang $R$, Wang $D$, Xia Z, et al. The role of microRNAs in adipocyte differentiation. Front Med. 2013;7:223-30.

44. Xia C, Yang Y, Kong F, Kong Q, Shan C. MiR-143-3p inhibits the proliferation, cell migration and invasion of human breast cancer cells by modulating the expression of MAPK7. Biochimie. 2014;147:98-104.

45. Bartholomeusz C, Gonzalez-Angulo AM, Liu P, Hayashi N, Lluch A Ferrer-Lozano J, Hortobágyi GN. High ERK protein expression levels correlate with shorter survival in triple-negative breast cancer patients. Oncologist. 2012;17:766-74

46. Pon CK, Firth SM, Baxter RC. Involvement of insulin-like growth factor binding protein-3 in peroxisome proliferator-activated receptor gamma-mediated inhibition of breast cancer cell growth. Mol Cell Endocrinol. 2015;399:354-61.

47. Dong T. Anticancer activities of PPARy in breast cancer are contextdependent. Am J Pathol. 2013;182:1-4.

48. Wei H, Cui R, Bahr J, et al. miR-130a Deregulates PTEN and Stimulates Tumor Growth. Cancer Res. 2017:77:6168-78

49. Kim YJ, Hwang SJ, Bae YC, Jung JS. MiR-21 regulates adipogenic differentiation through the modulation of TGF-beta signaling in mesenchymal stem cells derived from human adipose tissue. Stem Cells. 2009;27:3093-102.

50. Kim YJ, Hwang SH, Cho HH, Shin KK, Bae YC, Jung JS. MicroRNA 21 regulates the proliferation of human adipose tissue derived mesenchymal stem cells and high-fat diet-induced obesity alters microRNA 21 expression in white adipose tissues. J Cell Physiol. 2012;227:183-93.

51. Khaidakov M, Mehta JL. Oxidized LDL Triggers Pro-Oncogenic Signaling in Human Breast Mammary Epithelial Cells Partly via Stimulation of MiR-21. PLoS ONE. 2012;7:e46973. https://doi.org/10.1371/journ al.pone.0046973.

52. Wang M, Li L, Liu R, et al. Obesity-induced overexpression of miRNA-24 regulates cholesterol uptake and lipid metabolism by targeting SR-B1. Gene. 2018:668:196-203.

53. Lu K, Wang J, Song Y, Zhao S, Liu H, Tang D, et al. miRNA-24-3p promotes cell proliferation and inhibits apoptosis in human breast cancer by targeting p27Kip1. Oncol Rep. 2015;34:995-1002.

54. Han X, Li Q, Liu C, Wang C, Li Y. Overexpression miR-24-3p repressed Bim expression to confer tamoxifen resistance in breast cancer. J Cell Biochem. 2019;120:12966-76.

55. Karkeni E, Astier J, Tourniaire F, El Abed M, Romier B, Gouranton E, et al. Obesity-associated inflammation induces microRNA-155 expression in adipocytes and adipose tissue: outcome on adipocyte function. J Clin Endocrinol Metab. 2016;101:1615-26.

56. Zhang W, Chen CJ, Guo GL. MiR-155 promotes the proliferation and migration of breast cancer cells via targeting SOCS1 and MMP16. Eur Rev Med Pharmacol Sci. 2018;22:7323-32.

57. Qin L, Chen Y, Niu Y, et al. A deep investigation into the adipogenesis mechanism: Profile of microRNAs regulating adipogenesis by modulating the canonical Wnt/ $\beta$-catenin signaling pathway. BMC Genomics. 2010;11:320.

58. Tang T, Yang Z, Zhu Q, et al. Up-regulation of miR-210 induced by a hypoxic microenvironment promotes breast cancer stem cells metastasis, proliferation, and self-renewal by targeting E-cadherin [published online ahead of print, 2018 Sep 6]. FASEB J. 2018;f201801013R. https:// doi.org/10.1096/fi.201801013r.

59. Zhang Y, Yan J, Wang L, et al. HIF-1 a Promotes Breast Cancer Cell MCF-7 Proliferation and Invasion Through Regulating miR-210. Cancer Biother Radiopharm. 2017:32(8):297-301.

60. Li MY, Pan Sr, Qiu AY. Roles of microRNA-221/222 in type 2 diabetic patients with post-menopausal breast cancer. Genet and Mol Res 2016;15:4238/gmr.15027259.

61. Chen WX, Hu Q, Qiu MT, et al. miR-221/222: promising biomarkers for breast cancer. Tumour Biol. 2013;34:1361-70.

62. Wang DD, Yang SJ, Chen $X$, et al. miR-222 induces Adriamycin resistance in breast cancer through PTEN/Akt/p2 $7^{\text {kip } 1}$ pathway. Tumour Biol. 2016:37:15315-24.

63. Miller TE, Ghoshal K, Ramaswamy B, Roy S, Datta J, Shapiro CL, et al. MicroRNA-221/222 confers tamoxifen resistance in breast cancer by targeting p27Kip1. J Biol Chem. 2008:283:29897-903.

64. Zhao JJ, Lin J, Yang H, KongW, He L, Ma X, et al. MicroRNA-221/222 negatively regulates estrogen receptor alpha and is associated with tamoxifen resistance in breast cancer. J Biol Chem 2008; 283:31079-86.

65. Zong $Y$, Zhang $Y$, Sun $X, X u$ T, Cheng $X$, Qin Y. miR-221/222 promote tumor growth and suppress apoptosis by targeting IncRNA GAS5 in breast cancer. Biosci Rep. 2019; 39: BSR20181859.

66. Deiuliis JA. MicroRNAs as regulators of metabolic disease: pathophysiologic significance and emerging role as biomarkers and therapeutics. Int J Obes. 2016:40:88-101.

67. Rajarajan D, Selvarajan S, Charan Raja M, Mahapatra SK, Kasiappan R. Genome-wide analysis reveals miR-3184-5pandmiR-181c-3p as a critical regulator for adipocytes-associated breast cancer. J Cell Physiol. 2019;234:17959-74

68. Xu G, Ji C, Song G, et al. MiR-26b modulates insulin sensitivity in adipocytes by interrupting the PTEN/PI3K/AKT pathway. Int J Obe. 2015;39(10):1523-30. https://doi.org/10.1038/ijo.2015.95.

69. Liu XX, Li XJ, Zhang B, Liang YJ, Zhou CX, Cao DX, et al. MicroRNA-26b is underexpressed in human breast cancer and induces cell apoptosis by targeting SLC7A11. FEBS Lett. 2011;585:1363-7.

70. Tan S, Ding K, Li R, et al. Identification of miR-26 as a key mediator of estrogen stimulated cell proliferation by targeting CHD1, GREB1 and 
KPNA2. Breast Cancer Res. 2014; 16(2): R40. Published 2014. https://doi. org/10.1186/bcr3644.

71. Koh EH, Chernis N, Saha PK, et al. miR-30a remodels subcutaneous adipose tissue inflammation to improve insulin sensitivity in obesity. Diabetes. 2018;67:2541-53.

72. Karbiener M, Neuhold C, Opriessnig P, Prokesch A, Bogner-Strauss JG, Scheideler M. MicroRNA-30c promotes human adipocyte differentiation and co-represses PAI-1 and ALK2. RNA Biol. 2011;8:850-60.

73. Yang SJ, Yang SY, Wang DD, et al. The miR-30 family: versatile players in breast cancer. Tumour Biol. 2017;39:1010428317692204.

74. Sharma NK, Varma V, Ma L, Hasstedt SJ, Das SK. Obesity associated modulation of miRNA and co-regulated target transcripts in human adipose tissue of non-diabetic subjects. Microrna. 2015:4:194-204.

75. Li Y, Deng X, Zeng X, Peng X. The role of miR-148 in cancer. J Cancer. 2016;7:1233-124.

76. Picon-Ruiz M, Pan C, Drews-Elger K, Jang K, Besser AH, Zhao D, et al. Interaction between adipocyte and breast cancer cells stimulate cytokine production and drive Src/Sox2/miR-302b- mediated malignant progression. Cancer Res. 2016;76:491-504.

77. Ma J, Zhou Z. Downregulation of miR-302b is associated with poor prognosis and tumor progression of breast cancer. Breast Cancer. 2020;27:291-8.

78. Mayr C, Hemann MT, Bartel DP. Disrupting the pairing between let-7 and Hmga2 enhances oncogenic transformation. Science. 2007;315:1576-9.

79. Johnson SM, Grosshans H, Shingara J, Byrom M, Jarvis R, Cheng A, et al. RAS is regulated by the let-7 microRNA family. Cell. 2005;120:635-47.

80. O'Day E, Lal A. MicroRNAs and their target gene networks in breast cancer. Breast Cancer Res. 2010;12:201.

81. Chen T, Zhang Y, Liu Y, et al. MiR-27a promotes insulin resistance and mediates glucose metabolism by targeting PPAR- $\gamma$-mediated PI3K/AKT signaling. Aging. 2019;11(18):7510-24.

82. Lin Q, Gao Z, Alarcon RM, Ye J, Yun Z. A role of miR-27 in the regulation of adipogenesis. FEBS. 2009;276:2348-58

83. Li X, Xu M, Ding L, Tang J. MiR-27a: a novel biomarker and potential therapeutic target in tumors. J Cancer. 2019;10:2836-48.

84. Wang Y, Rathinam R, Walch A, Alahari SK. ST14 (suppression of tumorigenicity 14) gene is a target for miR-27b, and the inhibitory effect of ST14 on cell growth is independent of miR-27b regulation. J Biol Chem. 2009:284:23094-106.

85. Chen D, Si W, Shen J, Du C, Lou W, Bao C, et al. miR-27b-3p inhibits proliferation and potentially reverses multi-chemoresistance by targeting CBLB/GRB2 in breast cancer cells Cell Death Dis. 2018; 9:188.

86. Pan Y, Hui X, Hoo R, Ye D, Chan C, Feng T, et al. Adipocyte-secreted exosomal microRNA-34a inhibits M2 macrophage polarization to promote obesity-induced adipose inflammation. J Clin Invest. 2019;129:834-49.
87. Bommer GT, Gerin I, Feng Y, Kaczorowski AJ, Kuick R, Love RE, et al. p53-mediated activation of miRNA34 candidate tumor-suppressor genes. Curr Biol. 2007;17:1298-307.

88. Yamakuchi M, Ferlito M, Lowenstein CJ. miR-34a repression of SIRT1 regulates apoptosis. Proc Natl Acad Sci U S A. 2008;105:13421-6.

89. Rui X, Zhao H, Xiao X, Wang L, Mo L, Yao Y. MicroRNA-34a suppresses breast cancer cell proliferation and invasion by targeting Notch1. Exp Ther Med. 2018;16:4387-92.

90. Si W, Li Y, Shao H, et al. MiR-34a Inhibits Breast Cancer Proliferation and Progression by Targeting Wnt1 in Wnt/ $\beta$-Catenin Signaling Pathway. Am J Med Sci. 2016;352:191-9.

91. Yang S, Li Y, Gao J, et al. MicroRNA-34 suppresses breast cancer invasion and metastasis by directly targeting Fra-1. Oncogene. 2013:32:4294-303.

92. Christoffersen NR, Shalgi R, Frankel LB, Leucci E, Lees M, Klausen M, et al. p53 independent upregulation of miR-34a during oncogene-induced senescence represses MYC. Cell Death Differ. 2010;17:236-45.

93. Jasinski-Bergner S, Kielstein $\mathrm{H}$. Adipokine regulated the expression of tumor relevant microRNA. ObeseFact. 2019;12:211-25.

94. Blenkiron C, Goldstein LD, Thorne NP, Spiteri I, Chin SF, Dunning MJ, et al. MicroRNA expression profiling of human breast cancer identifies new markers of tumor subtype. Genome Biol. 2007;8:R214.

95. Rahman MM, Brane AC, Tollefsbol. MicroRNA and epigenetic strategies to reverse breast cancer. Cells. 2019; 8:1214.

96. Zografos E, Zagouri F, Kalapanida D, Zakoupolou R, Kyriazoglou A, Apostolidou K. Prognostic role of microRNA in breast cancer: a systematic review. Oncotarget. 2019:10:7156-77.

97. Peña-Cano MI, Saucedo R, Morales-Avila E, Valencia J, Zavala-Moha JA, López A. Deregulated microRNAs and Adiponectin in Postmenopausal Women with Breast Cancer. Gynecol Obstet Invest. 2019;84:369-77.

98. Carmichael AR, Bendall S, Lockerbie L, Prescott RJ, Bates T. Does obesity compromise survival in women with breast cancer? Breast. 2004;3:93-6.

99. Moore AH, Trentham-Dietz A, Burns M, et al. Obesity and mortality after locoregional breast cancer diagnosis. Breast Cancer Res Treat. 2018:172:647-57.

100. Gershuni V, Li YR, Williams AD, et al. Breast cancer subtype distribution is different in normal weight, overweight, and obese women. Breast Cancer Res Treat. 2017:163:375-81.

\section{Publisher's Note}

Springer Nature remains neutral with regard to jurisdictional claims in published maps and institutional affiliations.
Ready to submit your research? Choose BMC and benefit from:

- fast, convenient online submission

- thorough peer review by experienced researchers in your field

- rapid publication on acceptance

- support for research data, including large and complex data types

- gold Open Access which fosters wider collaboration and increased citations

- maximum visibility for your research: over 100M website views per year

At $\mathrm{BMC}$, research is always in progress.

Learn more biomedcentral.com/submissions 